\title{
Séminaire Edgar Morin : cheminement intellectuel et humain
}

Faculté d'Education de l'Université de Montpellier, Janvier-mars 2019

Faculté d'Education Université de Montpellier

\section{CpenEdition}

\section{Journals}

Édition électronique

URL : http://journals.openedition.org/trema/6367

DOI : $10.4000 /$ trema.6367

ISSN : 2107-0997

Éditeur

Faculté d'Éducation de l'université de Montpellier

Référence électronique

Faculté d'Education Université de Montpellier, «Séminaire Edgar Morin : cheminement intellectuel et humain », Tréma [En ligne], 54 | 2020, mis en ligne le 01 décembre 2020, consulté le 14 décembre 2020. URL : http://journals.openedition.org/trema/6367 ; DOI : https://doi.org/10.4000/trema.6367

Ce document a été généré automatiquement le 14 décembre 2020.

Trema 


\section{Séminaire Edgar Morin : cheminement intellectuel et humain}

Faculté d'Education de l'Université de Montpellier, Janvier-mars 2019

Faculté d'Education Université de Montpellier

\section{4 enregistrements en libre accès pour comprendre le cheminement intellectuel et humain d'un chercheur atypique}

1 Considérant qu'aucun problème important ne peut être traité d'un seul point de vue, au prisme d'une seule discipline, Edgar Morin a conceptualisé la notion de pensée complexe. Pour ce faire, il considère le développement de la pensée comme une activité de tissage, d'assemblage de connaissances diverses, issue de champs scientifiques différents. Refusant ainsi le repli sur soi, la centration sur une source ou un éclairage unique, le chercheur s'est efforcé d'élaborer une méthode offrant les moyens de relier, coordonner des éléments épars voire opposés.

2 Interrogeant au prisme de disciplines différentes qu'il croise, des questions fondamentales comme la mondialisation, l'identité humaine, l'éducation, le séminaire qu'Edgar Morin anime à la Faculté d'Education permet aux participants et aux auditeurs de mieux comprendre l'intérêt de ce concept pour en saisir les enjeux, les difficultés et s'approprier les méthodes utiles au développement de cette forme de pensée.

\section{Séance 1, 16 janvier 2019}

3 Cette première séance introductive a permis de définir la notion de connaissance complexe pour en saisir les principes essentiels.

4 https://video.umontpellier.fr/video/2443-seminaire-edgar-morin-14-le-defi-des-

complexites-problemes-et-methodes/ 


\section{Séance 2, 30 janvier 2019}

5 Cette deuxième séance interroge les expériences politiques, intellectuelles, personnelles exposant une genèse de la pensée complexe.

6 https://video.umontpellier.fr/video/2445-seminaire-edgar-morin-24-le-defi-descomplexites-problemes-et-methodes/

\section{Séance 3, 13 février 2019}

7 Cette troisième séance poursuit l'exposé $\mathrm{du}$ cheminement du chercheur : des rencontres vers l'écriture.

8 https://video.umontpellier.fr/faculte-deducation/seminaire-edgar-morin/video/2484seminaire-edgar-morin-34-le-defi-des-complexites-problemes-et-methodes/

\section{Séance 4, 13 mars 2019}

9 Cette quatrième séance interroge notamment les notions de construction de connaissance et de reliance.

10 https://video.umontpellier.fr/video/2558-seminaire-edgar-morin-44-le-defi-descomplexites-problemes-et-methodes/ 